\title{
Consideration of anisotropies related to bedding planes in the modelling of thick-walled hollow cylinder tests on Boom Clay
}

\author{
F. Peguiron ${ }^{a}{ }^{*}$ and V. Labiouse ${ }^{b}$
}

${ }^{a}$ GeoRessources, Université de Lorraine, Nancy, France; ${ }^{b}$ iTEC, School of Engineering and Architecture of Fribourg HEIA-FR, member of University of Applied Sciences and Arts Western Switzerland HES-SO, Fribourg, Switzerland

Corresponding author at: HEIA-FR, Boulevard de Perolles 80, 1700 Fribourg, Switzerland. Email : florence.peguiron@hefr.ch (F.Peguiron)

Tunnel excavation in Boom Clay formation, Belgium, highlighted an anisotropic behavior related to its bedding planes. Hollow cylinder tests mimicking tunnel excavation under laboratory conditions confirmed the isotropic convergence of samples cored perpendicular to the bedding and the anisotropic behavior of samples cored parallel to the bedding. This paper investigates the possibility to reproduce these observations by numerical modelling considering anisotropies related to weakness planes.

The behavior of samples cored perpendicular to the bedding are simulated using an isotropic elasto-plastic model. Despites of its simplicity, it shows good agreements with the experimental results. The results highlighted two competing phenomena: the hydromechanical coupling occurring during the unloading on the one hand, and the drainage towards the central hole on the other hand. Accordingly, the unloading rate is found to influence the displacement and the plastic zone extent.

Strength and hydraulic anisotropies are considered in the simulations of samples cored parallel to the bedding. However, numerical results are opposite to the experimental observations, both in terms of the maximum displacement orientation and the plastic zone extent. Stiffness anisotropy should be considered as it might affect the hydromechanical coupling and therefore influence where the plastification begins.

Keywords Hollow cylinder test; Numerical modelling; Anisotropy; Boom Clay 


\section{Introduction}

The disposal of high-level radioactive waste is a complex issue as very strict requirements are required to achieve a long-term security. Among the solutions investigated, their storage in deep geological formations is considered as highly promising.

Boom Clay formation has been studied in HADES underground research laboratory (URL) in Mol, Belgium, since 1976. Boom Clay is a marine deposit of the Rupelian stage (i.e. 33.9 to $28.4 \mathrm{Ma}$ ). At HADES URL in the North of Belgium, it lays at a depth of 220 meters. It is a hard, high plasticity, overconsolidated clay (Horseman and al. 1987). Boom Clay is mainly composed of clay minerals such as illite and smectite, but it also contains quartz and feldspars. Pyrite and calcite are present, in a lower proportion (Coll 2005).

The low permeability, self-sealing ability and chemical absorption capacity of Boom Clay make it particularly suitable to be used as a geological retention-barrier. However, the stress release occurring during the excavation of galleries disturbs locally the clay massif. A distinction is made between the excavation disturbed zone (EdZ) which does not have an impact on the long term safety, and the excavation damaged zone (EDZ) in which a significant change in the hydro-mechanical properties of the clay occurs (Blümling and al. 2007). During excavations, the formation of the EDZ may lead to local instabilities. In the context of radioactive waste disposal, it could also have an impact on the long-term performance of the repository, as the fractures created might be preferential paths for radionuclide migration. The EDZ has thus been carefully studied through major European projects, and complementary approaches have been used such as in-situ experiments, numerical modelling, laboratory tests or reduced scale simulations (Bastiaens and al. 2003, Bastiaens and al. 2007, Li 2013). Research results indicate that the EDZ would not affect the performance assessment of the repository (Blümling and al. 2007), however the understanding of the response of the clay massif around the excavation, including its anisotropic behavior, 
should be deepened to increase confidence in the current understanding of the on-going phenomenon occurring during the excavation, as well as the reliability of their modelling. In the framework of TIMODAZ project, thick-walled hollow cylinder tests were performed on Boom Clay and Opalinus Clay (Labiouse and al. 2014, Labiouse and Vietor 2014). These experiments aimed at reproducing at reduced scale the excavation of galleries and shafts by means of samples cored in the directions parallel and perpendicular to the bedding planes, respectively. The results for Boom Clay indicate that samples cored perpendicular to bedding have an isotropic convergence of the central hole. On the contrary, Boom Clay samples cored parallel to bedding have an anisotropic behavior, as a higher convergence was observed in the direction parallel to the bedding. These experimental observations are in accordance with in-situ observations conducted during the excavation of HADES URL, where a higher convergence was measured horizontally (i.e. parallel to the bedding planes) and the damaged zone was as well larger in the horizontal direction (Bastiaens and al. 2003). This could be related to mechanical anisotropy (strength and/or deformation) as well as to hydraulic anisotropy. Although the coefficient at rest $\mathrm{K}_{\mathrm{o}}$ is close to 1, the initial anisotropic stress field in the clay formation could also play a role. During the excavation of HADES URL a strong hydro-mechanical coupling due to Boom Clay low permeability has also been recorded. Piezometers installed in the clay formation indicated a slight increase followed by a significant drop of the pore water pressure as the tunnel front came closer. Moreover, an instantaneous pore water pressure variation was also recorded in the far field (Bernier 2003).

This paper questions the ability to reproduce the experimental observations by considering strength and permeability anisotropies related to Boom Clay laminate structure. Namely, the isotropic and anisotropic behaviors of Boom Clay observed during hollow cylinder tests on samples cored perpendicular and parallel to the bedding planes are compared 
with numerical simulations. A particular attention is paid on the convergence of the central hole and the extent of the plastic zone.

\section{TIMODAZ experimental results}

Excavation of galleries had been mimicked at reduced scale using thick-walled hollow cylinder samples with a central hole of $14 \mathrm{~mm}$, an external diameter of $86 \mathrm{~mm}$ and a total height of about $170 \mathrm{~mm}$ (Figure 1). The experimental device was a triaxial cell modified in order to apply pore water pressures and confinement pressures against the inner and the outer boundaries of the hollow cylinder. CPV instruments controlled the pressure of these four independent fluids. First, the in-situ stress conditions were uniformly recovered in the sample. At the depth of HADES URL (i.e. $220 \mathrm{~m}$ ), total stresses and pore water pressure before the excavation are 4.5 MPa and 2.2 MPa, respectively. To mimic the tunnel excavation, the inner confining pressure was decreased in 70 minutes from $4.5 \mathrm{MPa}$ to $1.0 \mathrm{MPa}$; this latter value is based on the pressure measured on the lining of galleries at HADES URL (Bastiaens and al. 2003). Simultaneously, the inner pore water pressure was decreased to nearly reach the atmospheric pressure (Table 1). Medical scans were carried out before and a few hours after the unloading to observe the displacements occurring in the sample. For each CT scan, the testing cell had been transported to the CHUV hospital, which is a few kilometers away. Further information is provided in Labiouse and al. 2014.

Table 1. Confinement and pore water pressures imposed during hollow cylinder tests

\begin{tabular}{lcc}
\hline Boundary pressure conditions & Before unloading & After unloading \\
\hline Inner confinement pressure $\sigma_{\text {int }}$ & $4.5 \mathrm{MPa}$ & $1.0 \mathrm{MPa}$ \\
Inner pore water pressure $p_{w \text { int }}$ & $2.2 \mathrm{MPa}$ & $0.1 \mathrm{MPa}$ \\
Outer confinement pressure $\sigma_{\text {ext }}$ & $4.5 \mathrm{MPa}$ & $4.5 \mathrm{MPa}$ \\
Outer pore water pressure $p_{w \text { ext }}$ & $2.2 \mathrm{MPa}$ & $2.2 \mathrm{MPa}$ \\
\hline
\end{tabular}

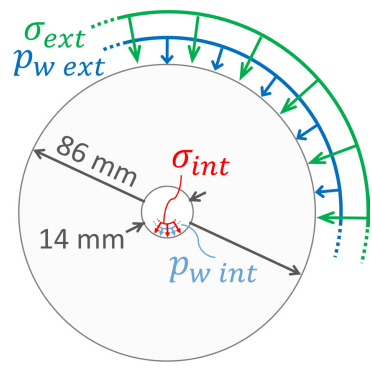

Figure 1. Thick hollow cylinder geometry 


\section{Sample $11 B$ perpendicular to the bedding}

Samples cored in the direction perpendicular to the bedding planes have been tested in order to simulate excavation of shafts. Radial displacement was measured every 10 degrees around the central hole by comparing CT scans performed before and after the unloading.

Convergence of the central hole observed on sample 11B confirms the transversally isotropic behavior of Boom Clay (Figure 2), with an average radial displacement of $0.5 \mathrm{~mm}$. Due to the medium resolution of the Medical scanner (voxel size of $0.215 \mathrm{~mm}$ ), the displacement field in the sample 11B could not be measured. Similar results have been obtained in recent experiments undertaken at HEIA-FR (Peguiron and Labiouse 2021).

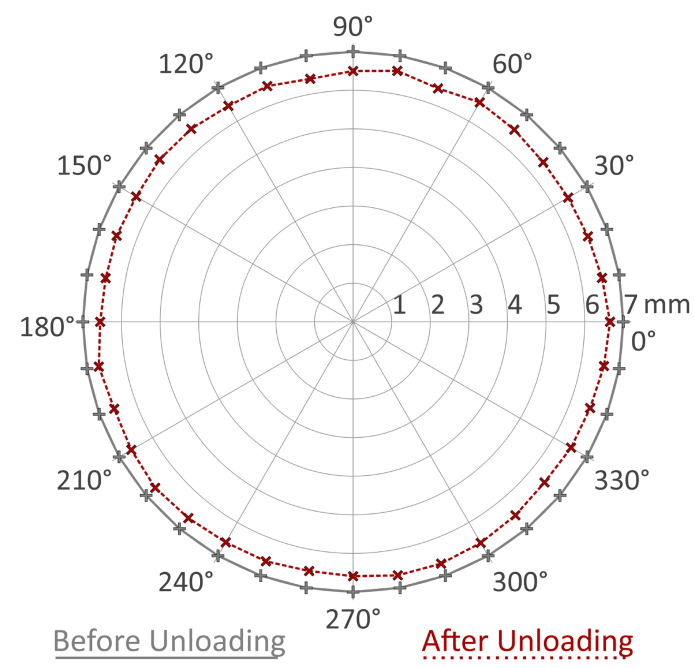

Figure 2. Central hole profile before and after unloading of sample 11B cored perpendicular to the bedding

\section{Sample 13 A parallel to the bedding}

Experiments were also conducted on samples cored in the direction parallel to the bedding planes to model horizontal galleries excavation. The following results come from sample 13A performed during TIMODAZ project (Labiouse and al. 2014). After unloading, a significant anisotropic convergence of the central hole is observed (Figure 3-left), with a higher displacement in the direction parallel to the bedding (about $3.9 \mathrm{~mm}$ ) than in the perpendicular 
direction $(1.7 \mathrm{~mm})$. However, at the outer boundary of the hollow cylinder, the opposite behavior is observed (Figure 3-right) as the displacement parallel to the bedding $(0.2 \mathrm{~mm})$ is smaller than the one in the perpendicular direction $(0.9 \mathrm{~mm})$.
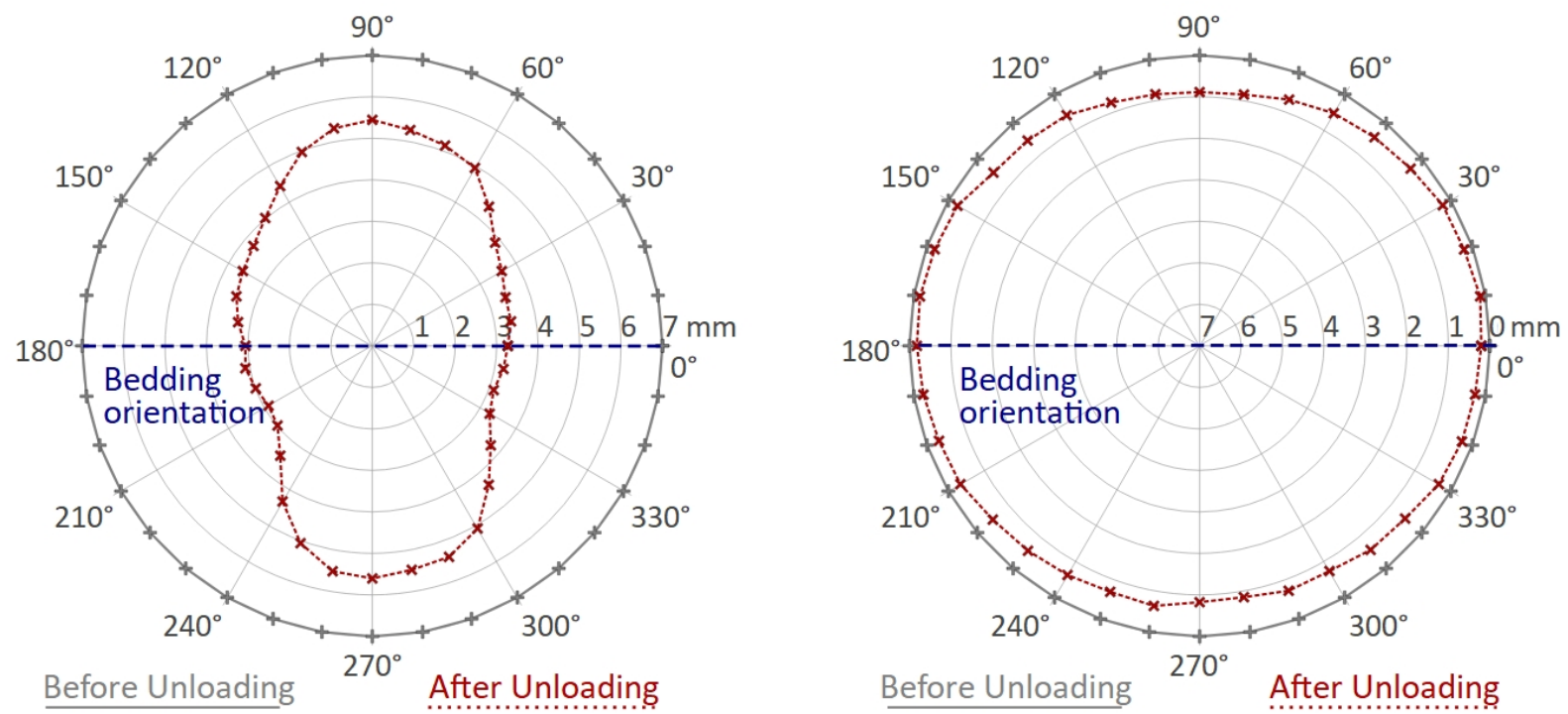

Figure 3. Central hole profile (left) and outer boundary convergence (right) of sample 13A cored parallel to the bedding

The displacement field in the sample had been estimated with two methods: Digital Volume Correlation method implemented in TomoWarp software that computes the displacement field in the whole sample (Hall 2006, Hall and al. 2009), and the Particle Manual Tracking method which consists of manually tracking pyrite inclusions and measuring their displacement (You and al. 2015). The displacement profiles obtained with the latter method highlight an eye-shaped damaged zone around the central hole in which significant displacements occur (Figure 4). These profiles also confirm the anisotropic convergence measured at the inner and outer boundaries. Such an anisotropic behavior has been as well observed in experiments recently performed at HEIA-FR (Peguiron and Labiouse 2021). 

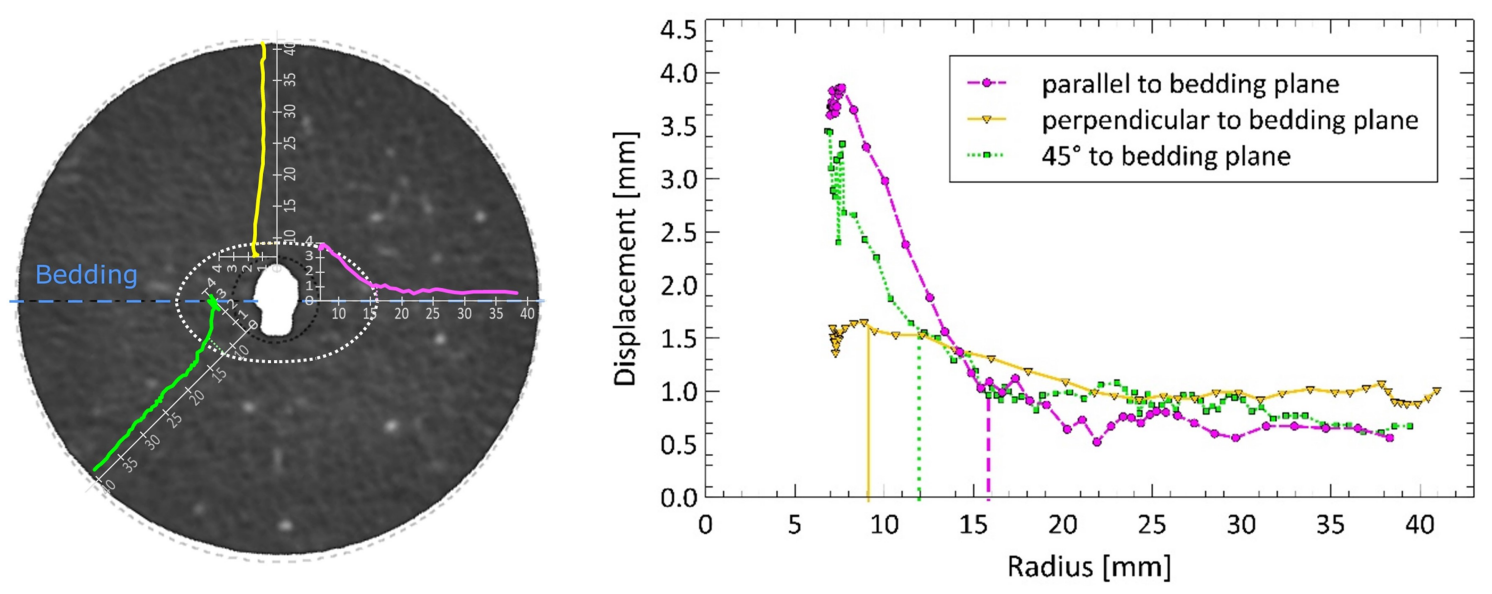

Figure 4. Displacement measured in the directions parallel (magenta), perpendicular (yellow), and at $45^{\circ}$ (green) to the bedding planes on sample 13A. The damaged zone extent is delimited according to the slope discontinuity observed on the displacement profiles.

These experimental results are in accordance with in-situ measurements at HADES URL, Belgium (Bastiaens and al. 2003). Around horizontal galleries in Boom Clay formation, an excavation induced damaged zone (EDZ) consisting of conjugated shear planes was found to extend more in the horizontal plane (i.e. parallel to bedding). A higher convergence was as well observed horizontally. Instead, the EDZ and the convergence around shafts and vertical boreholes were found to be axisymmetric.

As the hollow cylinder tests were conducted under isotropic pressure conditions, the orientation-dependent response of Boom Clay may only be caused by the inherent crossanisotropy that characterizes sedimentary deposits.

\section{Numerical Modelling}

Based on these experimental observations, numerical simulations are performed to determine whether the strength and/or permeability anisotropies related to the bedding planes could explain the observed orientation-dependent response and gain further understanding of the mechanism involved during the experiments. First, hollow cylinder tests on samples cored 
perpendicular to the bedding planes are modeled with an isotropic linear elastic perfectly plastic constitutive law. Then, tests on samples cored parallel to the bedding planes are simulated by taking into account the strength and permeability anisotropies of Boom Clay related to its weakness planes.

During tunnel excavation in a porous media with low permeability, the response of the massif is mainly governed by the hydro-mechanical coupling. The further numerical simulations will thus consider a fully coupled hydro-mechanical analysis.

It is worth noting that computations performed with a hardening/softening DruckerPrager model considering elastic and plastic cross-anisotropy have provided relatively good agreements with experimental results (François and al. 2014). However, this approach is not very satisfactory from a phenomenological point of view, as the cohesion is considered to depend on the angle between the bedding planes and the direction of major principal stress, with the lowest value taken arbitrarily at $45^{\circ}$. In this paper, the inherent anisotropy of Boom Clay is taken into account by assigning different properties in the bedding planes.

\section{Isotropic model}

As the sample 11B cored perpendicular to the bedding shows isotropic response during the experimental test, an isotropic linear elastic perfectly plastic constitutive law with a MohrCoulomb failure criterion is adopted to numerically model it. Parameters used in the model are given in Table 3 under "matrix" and "hydraulic" sections. The clay remains fully saturated all along the simulation.

A quarter of a hollow cylinder at mid-height of the sample and under plane strain conditions is considered. Confinement pressures and pore water pressures are imposed on the inner and outer boundaries. The unloading is simulated by decreasing both confinement and pore water pressures acting on the inner hole while the pressures on the outer boundary remain constant (Figure 5). The unloading time is the same as in the TIMODAZ hollow 
cylinder tests (i.e. 70 minutes). As experiments have been conducted recently at HEIA-FR with a faster unloading rate, a calculation with an unloading time of 5 minutes is also performed.
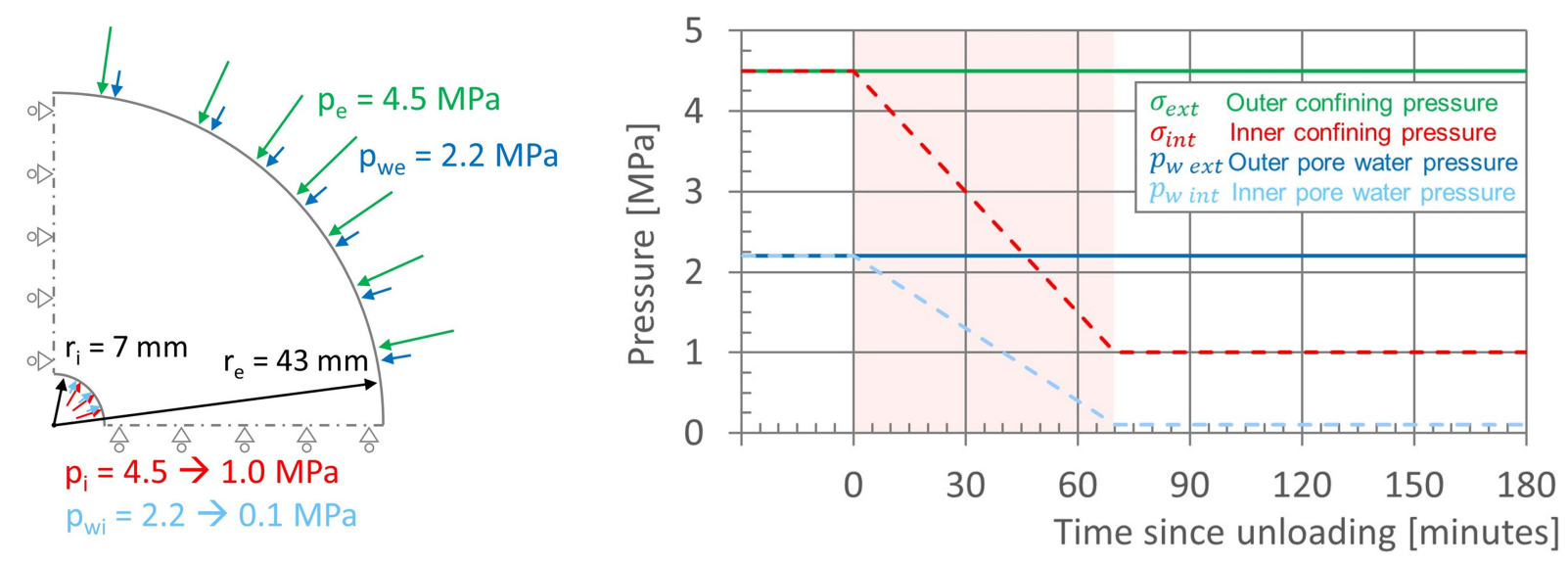

Figure 5. Boundary conditions (left) and evolution of imposed pressures during the 70minutes unloading (right)

In order to check the validity of the numerical model, another computation was performed with an instantaneous unloading and compared to a recently-developed analytical solution for the undrained unloading of poro-elastoplastic hollow cylinders (Peguiron and Labiouse 2020). The results match very well in terms of stresses, pore pressure, radial displacement and strains.

\section{Anisotropic models}

The anisotropic behavior of samples cored in the direction parallel to the bedding planes reflects the inherent anisotropy of Boom Clay as the tests are conducted under isotropic pressure conditions. Similarly, conventional triaxial tests performed on Boom Clay full cylinders have highlighted an anisotropic behavior and the influence of the bedding planes orientation on the shear strength (Dao 2015). 
Among the various constitutive models considering mechanical anisotropy of geomaterials (e.g. François and al. 2014, Oka and al. 2002), a rock mechanics-oriented failure criterion is adopted (Jaeger 1960, Sainsbury and Sainsbury 2017, Truty and al. 2018), in which spatially fixed preferential failure orientations can be introduced (i.e. weakness planes). The model has two components: i) a "matrix" constitutively similar to the isotropic model (i.e. an isotropic linear elastic perfectly plastic continuum with a Mohr-Coulomb failure criterion), and ii) weakness planes with a specific orientation and reduced Mohr-Coulomb strength parameters $c^{\prime}{ }_{\mathrm{w}}$ and $\varphi^{\prime}{ }_{\mathrm{w}}$. Depending on the orientation of the principal stresses with respect to the bedding planes, the failure may occur either in the matrix or along the planes of weakness. Equations 1 and 2 express the major principal effective stress at failure in the matrix and along the weakness planes respectively.

$$
\begin{array}{ll}
\text { Matrix } & \sigma^{\prime}{ }_{1 f}=\left[\frac{1+\sin \varphi^{\prime}}{1-\sin \varphi^{\prime}}\right]{\sigma^{\prime}}_{3}+2 c^{\prime} \sqrt{\frac{1+\sin \varphi^{\prime}}{1-\sin \varphi^{\prime}}} \\
\text { Weakness planes } & \sigma_{1 f}^{\prime}=\left[\frac{\tan \left(\alpha+\varphi^{\prime}{ }_{w}\right)}{\tan (\alpha)}\right]{\sigma^{\prime}}_{3}+\left[\frac{2 c^{\prime}{ }_{w} \cdot \cos \varphi^{\prime}{ }_{w}}{\sin \left(2 \alpha+\varphi^{\prime}{ }_{w}\right)-\sin \varphi^{\prime}{ }_{w}}\right]
\end{array}
$$

Figure 6 illustrates the corresponding failure criterion as a function of the orientation of the bedding planes $\alpha$ with respect to the major principal stress. The curve related to the slip on the weakness planes has two vertical asymptotes at $0^{\circ}$ and $\left(90^{\circ}-\varphi^{\prime}{ }_{w}\right)$ and a minimum for a value of $\alpha=\left(45^{\circ}-\varphi^{\prime}{ }_{w} / 2\right)$ 

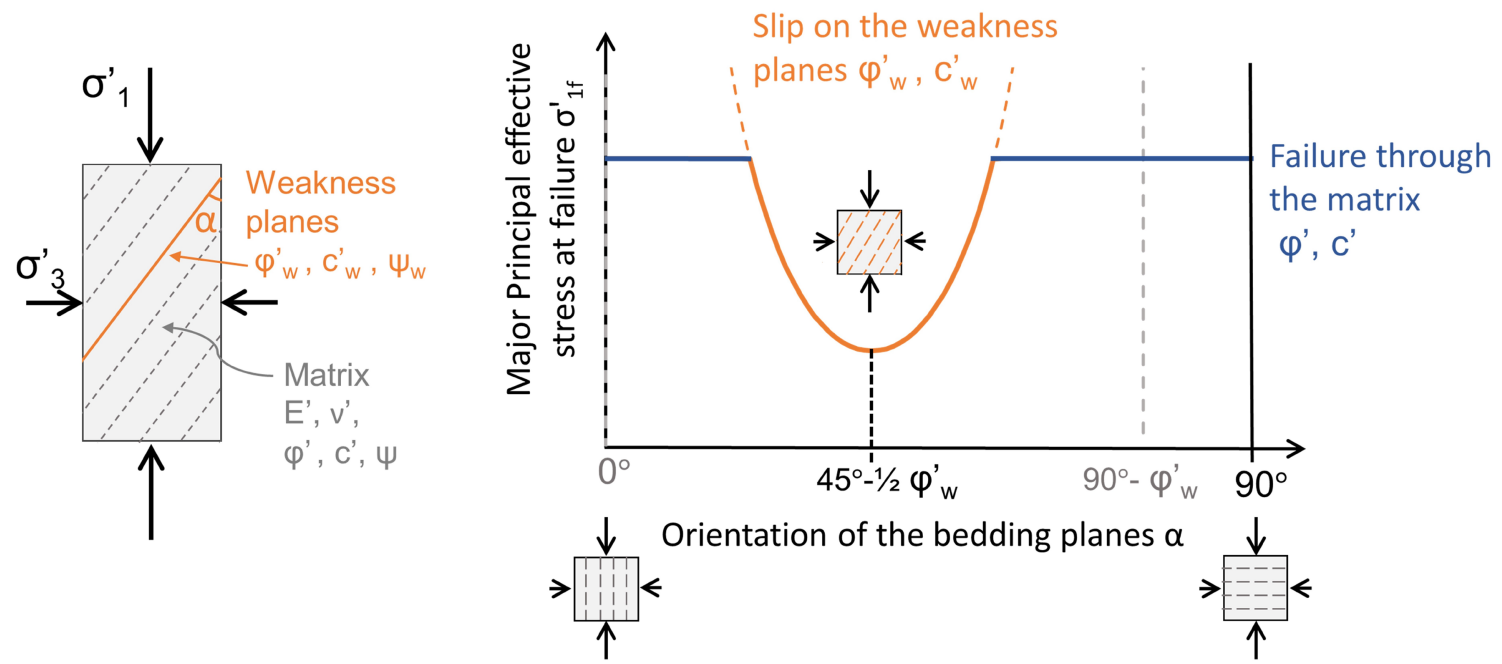

Figure 6 : Sample subjected to triaxial testing conditions (left). Major principal stress at failure as a function of its orientation $\alpha$ with respect to the weakness planes. It should be noted that the strength also depends on the magnitude of the minor principal effective stress (see Equations 1 and 2).

Hydraulic anisotropy is taken into account by setting a different value for the coefficient of permeability in the direction parallel and perpendicular to the bedding planes. All computations are performed with a fully coupled hydro-mechanical analysis. Tables 2 and 3 summarize respectively the main features of the performed simulations and the Boom Clay properties considered for the different models. The values assigned to the matrix and the hydraulic properties were obtained by back-analyses of laboratory tests and in-situ measurements (Bernier and al. 2007). Along the weakness planes, the strength parameters were adjusted to stay in accordance with thick-walled hollow cylinder and triaxial tests results (Labiouse and al. 2014, and Dao 2015). Overall, the parameters considered for the anisotropic simulations are in agreement with the ones of François and al. 2014. 
Table 2. List of performed simulations

\begin{tabular}{|c|c|c|c|c|c|c|}
\hline \multirow{2}{*}{$\begin{array}{l}\text { Computation } \\
\text { number }\end{array}$} & \multirow[t]{2}{*}{ File reference name } & \multicolumn{2}{|c|}{ Matrix } & \multirow{2}{*}{$\begin{array}{l}\text { Weakness } \\
\text { planes }\end{array}$} & \multirow[t]{2}{*}{ Permeability } & \multirow{2}{*}{$\begin{array}{c}\text { Unloading } \\
\text { time }\end{array}$} \\
\hline & & Elastic & Plastic & & & \\
\hline$\# 1$ & isotropic_70min & $E^{\prime}, v^{\prime}$ & $\varphi^{\prime}, c^{\prime}, \psi$ & - & $\mathrm{k}$ & $70 \mathrm{~min}$ \\
\hline$\# 2$ & isotropic_5min & $E^{\prime}, v^{\prime}$ & $\varphi^{\prime}, c^{\prime}, \psi$ & - & $\mathrm{k}$ & $5 \mathrm{~min}$ \\
\hline$\# 3$ & aniso_strength & $E^{\prime}, v^{\prime}$ & $\varphi^{\prime}, c^{\prime}, \psi$ & $\varphi_{\mathrm{w}}^{\prime}, \mathrm{c}_{\mathrm{w}}^{\prime}, \psi_{\mathrm{w}}$ & $\mathrm{k}$ & $70 \mathrm{~min}$ \\
\hline$\# 4$ & aniso_perm & $E^{\prime}, v^{\prime}$ & $\varphi^{\prime}, c^{\prime}, \psi$ & - & $\mathrm{k}_{/ /}, \mathrm{k}_{\perp}$ & $70 \mathrm{~min}$ \\
\hline$\# 5$ & aniso_strength_perm & $E^{\prime}, v^{\prime}$ & $\varphi^{\prime}, c^{\prime}, \psi$ & $\varphi_{\mathrm{w}}^{\prime}, \mathrm{c}_{\mathrm{w}}^{\prime}, \psi_{\mathrm{w}}$ & $\mathrm{k}_{/ /}, \mathrm{k}_{\perp}$ & $70 \mathrm{~min}$ \\
\hline
\end{tabular}

Table 3. Values of Boom Clay parameters considered for modelling

\begin{tabular}{|c|c|c|c|c|c|}
\hline \multicolumn{3}{|c|}{ Matrix } & \multicolumn{3}{|c|}{ Weakness planes } \\
\hline Cohesion & $\mathrm{c}^{\prime}$ & $300 \mathrm{kPa}$ & Cohesion & $\mathrm{c}_{\mathrm{w}}{ }^{\prime}$ & $240 \mathrm{kPa}$ \\
\hline Friction angle & $\varphi^{\prime}$ & $18^{\circ}$ & Friction angle & $\varphi_{\mathrm{w}}{ }^{\prime}$ & $16^{\circ}$ \\
\hline Dilation angle & $\psi$ & $0^{\circ}$ & Dilation angle & $\psi_{\mathrm{w}}$ & $0^{\circ}$ \\
\hline Young's modulus & $E^{\prime}$ & $300 \mathrm{MPa}$ & & & \\
\hline Poisson's ratio & $v^{\prime}$ & $0.125[-]$ & & & \\
\hline
\end{tabular}

\begin{tabular}{lcr}
\hline \multicolumn{3}{c}{ Hydraulic } \\
\hline Water bulk modulus & $\mathrm{K}_{\mathrm{w}}$ & $2 ’ 000 \mathrm{MPa}$ \\
Porosity & $\mathrm{n}$ & $0.39[-]$ \\
Permeability & $\mathrm{k}$ & $4 \cdot 10^{-12} \mathrm{~m} / \mathrm{s}$ \\
& $\mathrm{k}_{/ /}$ & $4 \cdot 10^{-12} \mathrm{~m} / \mathrm{s}$ \\
& $\mathrm{k}_{\perp}$ & $2 \cdot 10^{-12} \mathrm{~m} / \mathrm{s}$ \\
\hline
\end{tabular}

\section{Numerical results and discussion}

\section{Simulation of sample 11B - Isotropic model}

Despites of its simplicity, the isotropic linear elastic perfectly plastic constitutive model adopted gives a radial displacement in accordance with the displacement of $0.5 \mathrm{~mm}$ measured on sample 11B, cored in the direction perpendicular to the bedding planes (Figure 7-left).

Due to Boom Clay low permeability, a strong hydro-mechanical coupling occurs during the unloading. As stresses and pore water pressure cannot be measured experimentally 
inside the sample, numerical modelling may provide further information to understand the hydro-mechanical behavior of Boom Clay during the hollow cylinder tests.
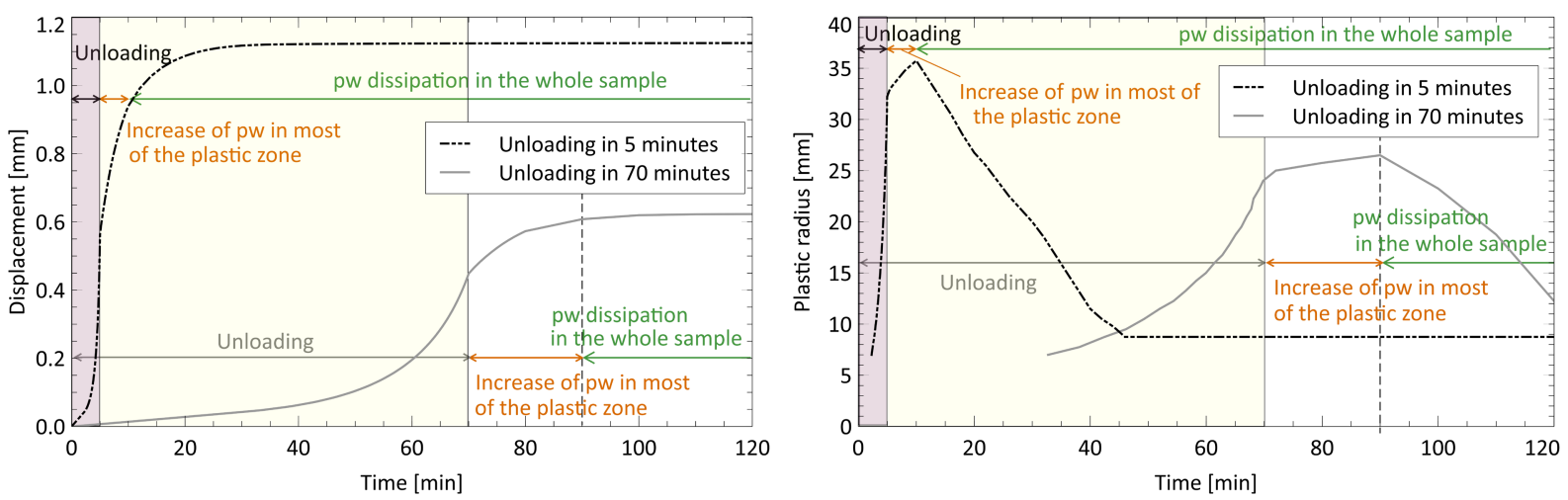

Figure 7. Radial displacement (left) and plastic radius (right) over time. Three phases are distinguished: unloading (black/grey), increase of pore water pressure in most of the plastic zone (orange), and pore water pressure dissipation in the whole sample (green) - isotropic model \#1 and \#2
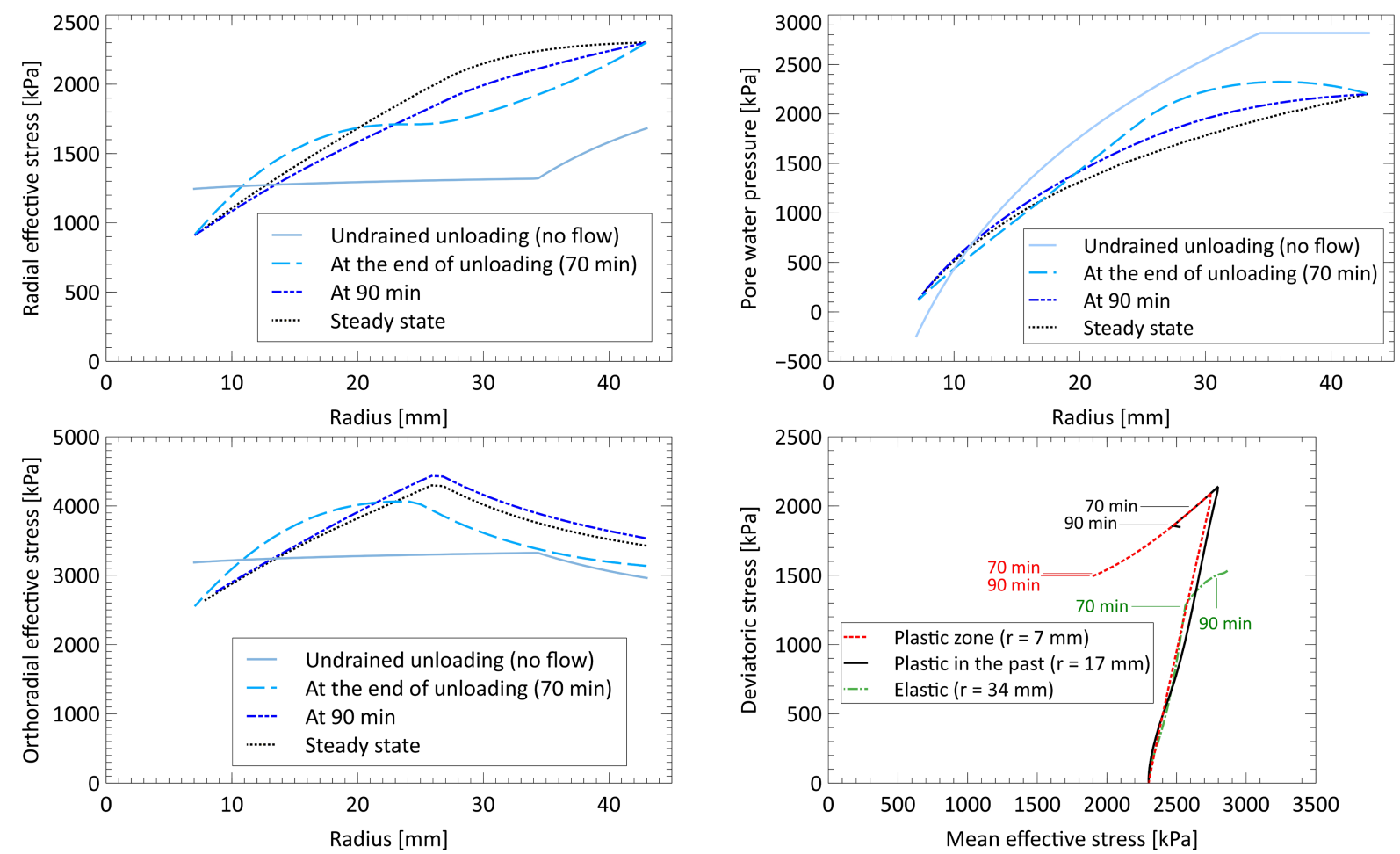

Figure 8. Radial and orthoradial effective stress profiles (left) and pore water pressure profiles (top right) for an isotropic model with a 70-minutes unloading (\#1). The undrained response calculated analytically (light blue line) is compared with the profiles at the end of the unloading (cyan), at $90 \mathrm{~min}$ (when Rpl is maximum (dark blue)), and at steady state flow 
(black). Deviatoric stress versus mean effective stress for elements located at various distances from the central hole (bottom right) : in the plastic zone (red), in a plastic zone that returns to an elastic state (black), in the elastic zone (green).

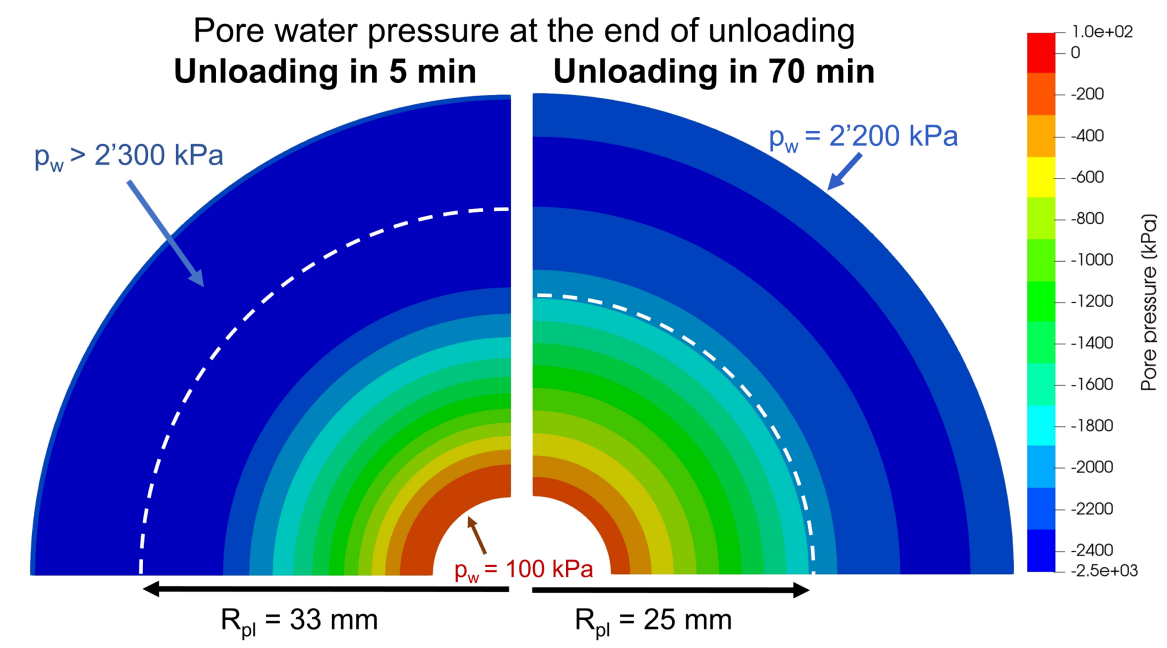

Figure 9. Pore water pressure at the end of unloading. Unloading in 5 minutes \#2 (left) and unloading in 70 minutes \#1 (right). The white dashed lines represent the extent of the plastic zone.

The unloading consists of a reduction of both the confining pressure $p_{i}$ and the pore water pressure $p_{w i}$ in the central hole. The hydro-mechanical response of Boom Clay sample depends on two competing phenomena. The first one is the hydro-mechanical coupling generated by the volumetric strain change occurring during the mechanical unloading. It is particularly strong for a fast unloading rate, because the excess pore water pressure induced by the volumetric strain change has no time to dissipate. The other one is related to the water flow towards the central hole where the pore water pressure has been decreased. For this second phenomenon, the lower the unloading rate, the closer the pore water pressure is to the steady state flow curve, because of the slow volumetric strain change that induces almost no excess pore water pressure in the sample.

After the end of the 70-minutes unloading, as the excess pore water pressure dissipates, pore pressure increases in the plastic zone and thus reduces both the mean effective 
stress and the shear strength in that zone. Therefore, the plastic zone extends a bit further and additional displacements occur (Figure 7).

From 90 minutes on, the pore water pressure decreases everywhere in the sample and approaches the steady state flow (Figure 8). Consequently, the mean effective stress and the shear strength increase in the whole sample, and a major part of the plastic zone becomes elastic again. A similar return of the plastic zone to an elastic state has already been pointed out in computations of tunnel instantly excavated in an infinite media, if drainage and free displacement at the excavated surface are imposed as long-term conditions (Giraud and al. 1993).

The stress path experienced by elements depends on their distance from the central hole (Figure 8-bottom right). An element located at the inner boundary reaches plasticity during the unloading and will remain in that state afterwards, unlike elements located further away that reach plasticity during the unloading but go back to an elastic state when the pore water pressure dissipates in the whole sample. Elements far enough from the central hole remain in an elastic state and their mean effective stress will increase after the unloading due to pore pressure decrease.

Numerical results for a 5-minutes unloading show that a faster unloading rate increases both the radial displacement and the extent of the damaged zone (Figure 7 and Figure 9). As a decrease in the volumetric strain occurs in the elastic zone due to the hollow cylinder geometry, a significant increase in pore water pressure occurs in that part of the sample if the unloading is rapid compared to the dissipation of pore water pressure (Figure 8top right). This temporarily reduces the mean effective stress and the shear strength, and leads to an increase in both the plastic zone extent and the displacements. This is consistent with observations in hollow cylinder tests recently performed at HEIA-FR with different unloading rate (Peguiron and Labiouse 2021). 
To determine whether these observations depend on the hollow cylinder geometry, numerical simulations of a cylindrical cavity in an infinite medium were performed with the same pressure conditions and for unloading times of 5 and 70 minutes. A similar influence was observed, but as no volumetric strain occurs in the elastic zone of an infinite medium subjected to an isotropic in-situ stress field, the change in pore pressure is smaller than for hollow cylinders. Accordingly, the plastic zone extent and the radial convergence are smaller and the influence of the unloading rate is not as strong.

\section{Simulation of sample $13 A$ - Anisotropic models}

The anisotropic behavior of Boom Clay samples cored parallel to the bedding planes is caused by its inherent anisotropy. Numerical results of models taking into account strength and/or hydraulic anisotropies related to the bedding planes are compared with experimental measurements of the displacement and the damaged zone. In the models, the bedding planes are introduced horizontally.

As concerns the model \#5 that takes into account both strength and hydraulic anisotropies, it provides similar results, and therefore cannot correctly reproduce the experimental observations either.

\section{Strength anisotropy}

Convergence along the directions parallel and perpendicular to the bedding planes shows a higher radial displacement near the central hole in the direction perpendicular to the bedding planes. And instead, a lower radial displacement occurs at the outer boundary (Figure 10right, Figure 11-left), which is the exact opposite of the experimental observations ! So it is for the extent of the plastic zone. 


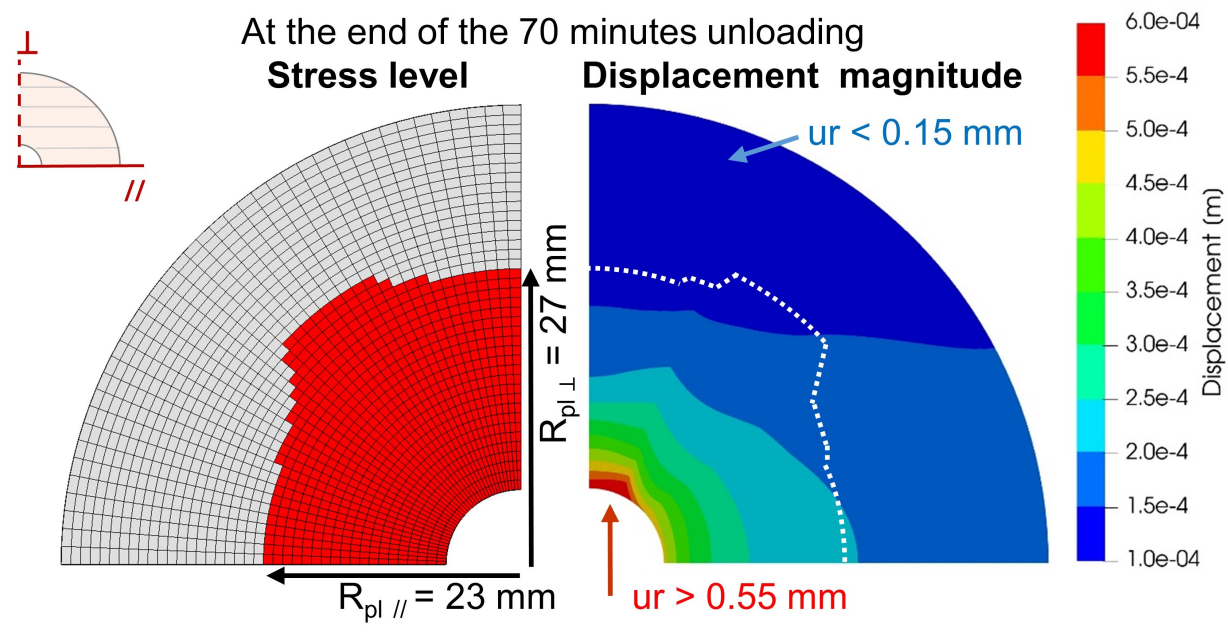

Figure 10. Plastic zones and displacement magnitude at the end of the unloading - Strength anisotropic model (\#3). The white dashed lines represent the extent of the plastic zone.
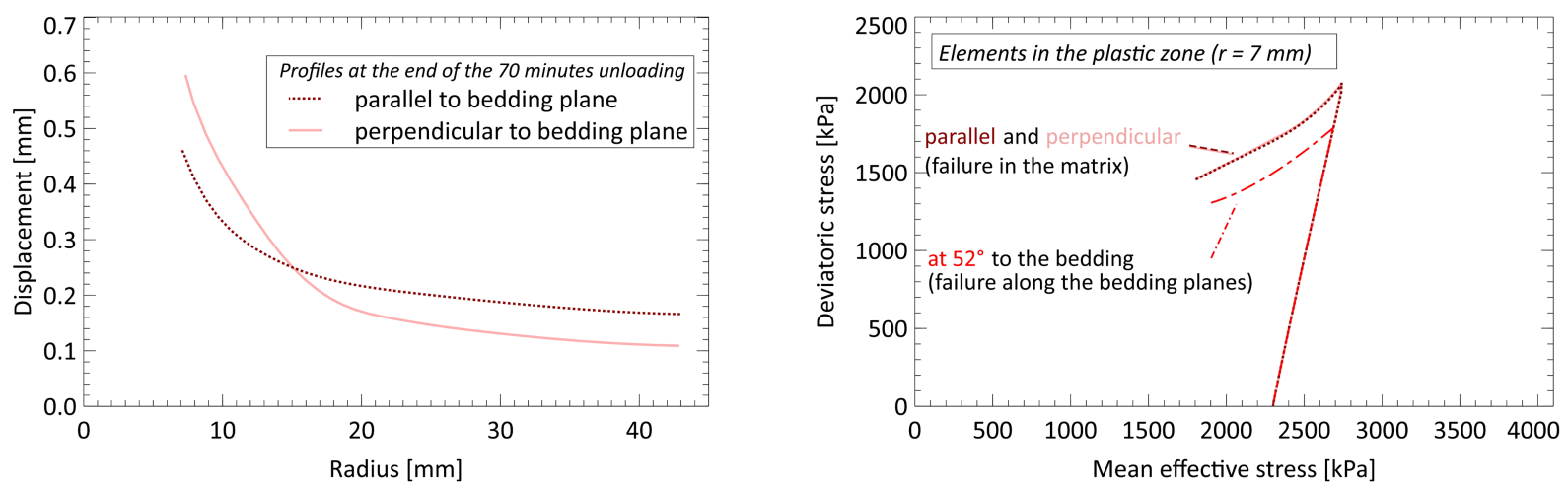

Figure 11. Convergence at the end of the unloading in the directions parallel and perpendicular to the bedding (left). Deviatoric stress versus mean effective stress for elements located at $0^{\circ}, 52^{\circ}$ and $90^{\circ}$ to the bedding, at the inner boundary (right) - Strength anisotropic model (\#3)

These numerical results performed with ZSoil Multilaminate model (Truty and al. 2018) that accounts for the strength anisotropy related to the bedding planes indicate an initiation of the plastification at an angle of $52^{\circ}$ to the bedding planes (Figure 10-left). This corresponds to the minimal shear strength with a failure occurring along the bedding where both the cohesion and the friction angle are reduced. On the other hand, where the principal 
stresses are parallel - or perpendicular - to the bedding, the failure occurs in the matrix (Figure 11-right).

Strength anisotropy alone cannot reproduce experimental observations both in terms of the orientation of the maximum displacement and the extent of the plastic zone. This statement is not software dependent as similar results were obtained with the Ubiquitous Joint model implemented in the finite difference program FLAC (Kivell 2015).

\section{Hydraulic anisotropy}

Hydraulic anisotropy is introduced through a lower permeability coefficient in the vertical direction (i.e. perpendicular to the bedding). As for the strength anisotropic model, the radial displacement profiles show opposite behavior to experimental observations with higher convergence of the central hole along the direction perpendicular to the bedding (Figure 13right, Figure 14-left). Similarly, the plastic zone extent is higher in the perpendicular direction (Figure 12-right, Figure 13-left).

Lowering the permeability has a similar effect as increasing the unloading rate: with a lower permeability coefficient, the unloading generates more pore water pressure variation in the sample, which leads to a larger extent of the plastic zone and an increase of the overall displacement.

The pore water pressure profiles at the end of the unloading (Figure 14-right) confirm that the pore water pressure is higher in the direction perpendicular to the bedding planes, and substantially increases in the elastic zone. On the contrary, in the direction parallel to the bedding planes, the effect of hydro-mechanical coupling is not as strong as in the perpendicular direction. And by the end of the unloading, a major part of the plastic zone developed horizontally becomes elastic again (Figure 13-left). This is mainly caused by a faster drainage of the water in that area, as the permeability is higher horizontally. 

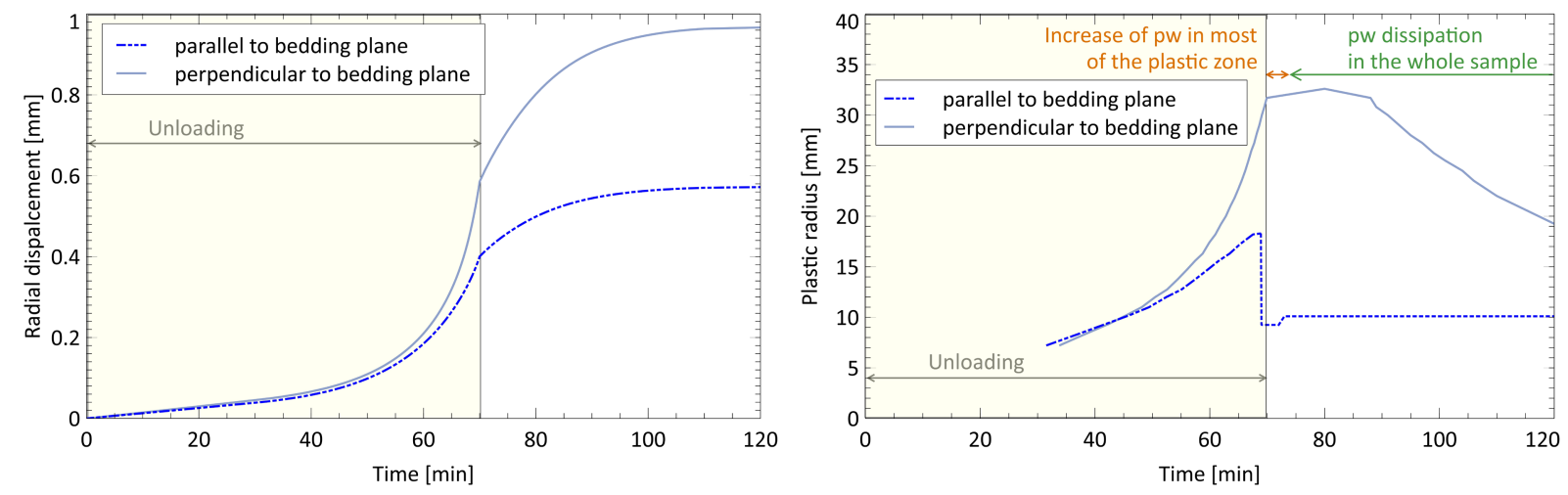

Figure 12. Radial displacement (left) and plastic radius (right) over time - hydraulic anisotropic model (\#4).

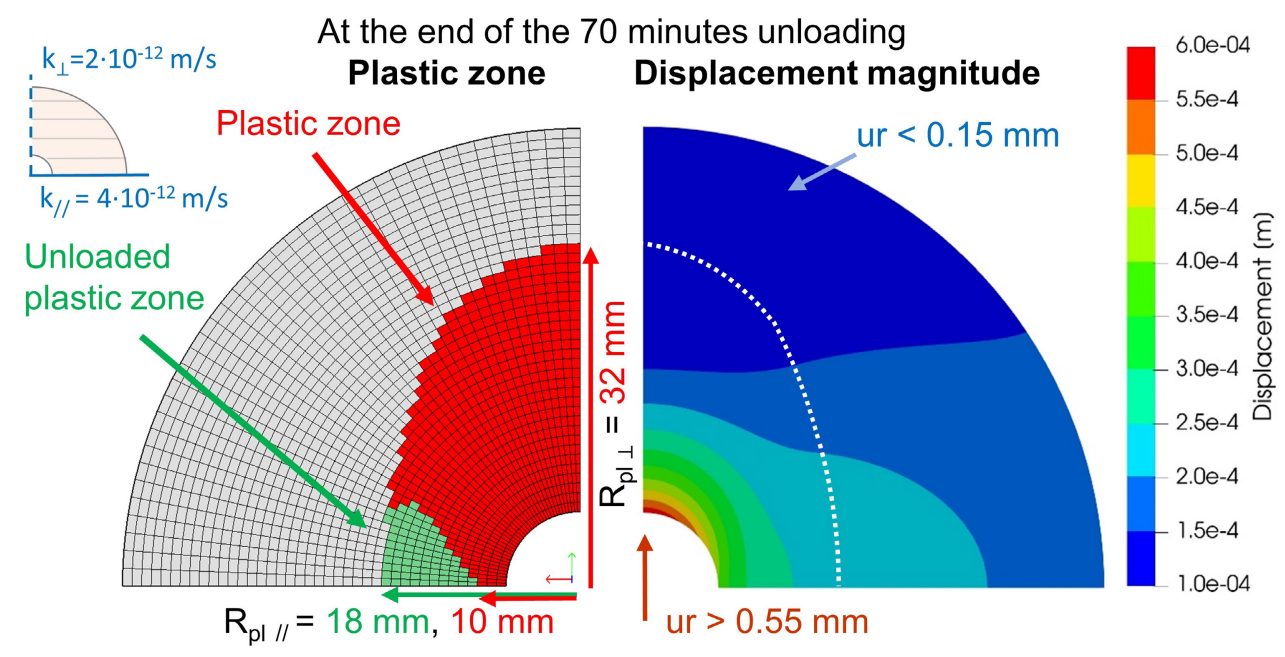

Figure 13. Plastic zones and displacement magnitude at the end of the unloading - hydraulic anisotropic model (\#4).
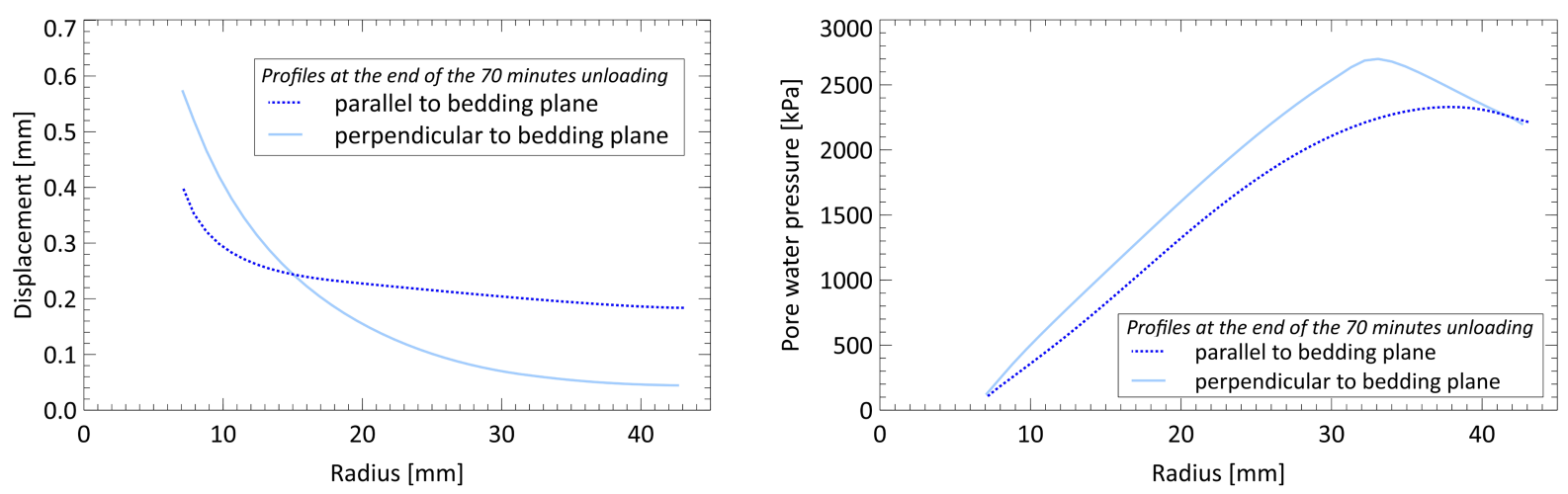

Figure 14. Convergence and pore water profiles at the end of the unloading in the directions parallel (dark blue) and perpendicular (light blue) to the bedding planes. 
As concerns the model \#5 that takes into account both strength and hydraulic anisotropies, it provides similar results, and therefore cannot correctly reproduce the experimental observations either.

Numerical simulations of a cylindrical cavity in an infinite medium were performed with the same pressure conditions for both strength and hydraulic anisotropic models. The same general behavior is observed, indicating that the higher convergence and the larger extent of the plastic zone in the horizontal direction are not caused by the hollow cylinder geometry.

\section{Comparison with experimental results}

Both experimental and numerical results show a larger average convergence of the clay around the central hole when anisotropy is considered due to the loss of axisymmetric conditions. However, numerical models taking into account both strength and/or hydraulic anisotropy predict a larger convergence and extent of the plastic zone in the direction perpendicular to the bedding, which is the opposite of the experimental and in-situ observations (Figure 15-left). At the outer boundary of the hollow cylinder, the numerical results are as well in the wrong direction, with a maximum displacement in the direction parallel to the bedding (Figure 15-right). 

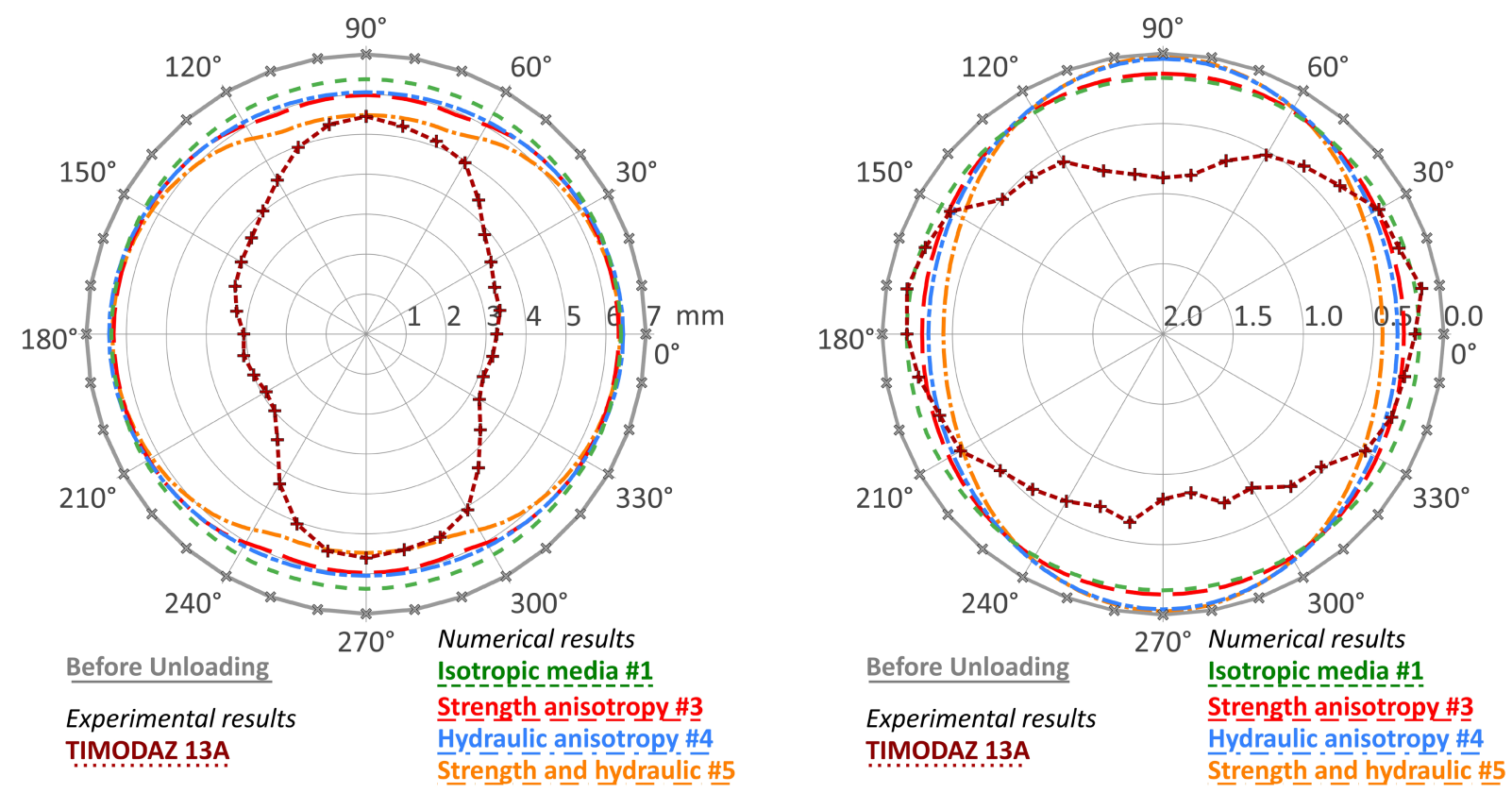

Figure 15. Comparison between numerical results (\#1, 3, 4 and 5) and experimental measures at the end of unloading of sample 13A. Convergence of the central hole (left) and displacement of the outer boundary (right). Pay attention to the different scales.

\section{Consideration of stiffness anisotropy}

So far, stiffness anisotropy was not considered. However, as this type of anisotropy is present from the beginning of the unloading, it might significantly affect the hydro-mechanical coupling and influence where the plastification begins.

As stiffness anisotropy is not implemented so far in ZSoil, a simulation using FLAC software stiffness anisotropic model was performed. This model is a cross-anisotropic linear purely elastic model. Based on back-analysis from in-situ testing performed in the framework of ATLAS III project (Cheng and al. 2011), a ratio of two is considered for the Young's modulus anisotropy $\left(E_{/ /}=2 \cdot E_{\perp}=400 \mathrm{MPa}\right)$.

The results indicate that an unloading under undrained conditions induces an increase of pore water pressure due to the volume contraction near the central hole in the direction parallel to the bedding planes (Figure 16). Therefore, the mean effective stress and the shear 
strength significantly decrease in this area and can initiate a failure. Conversely, the volume expansion in the direction perpendicular to the bedding increases temporarily the shear strength near the central hole.
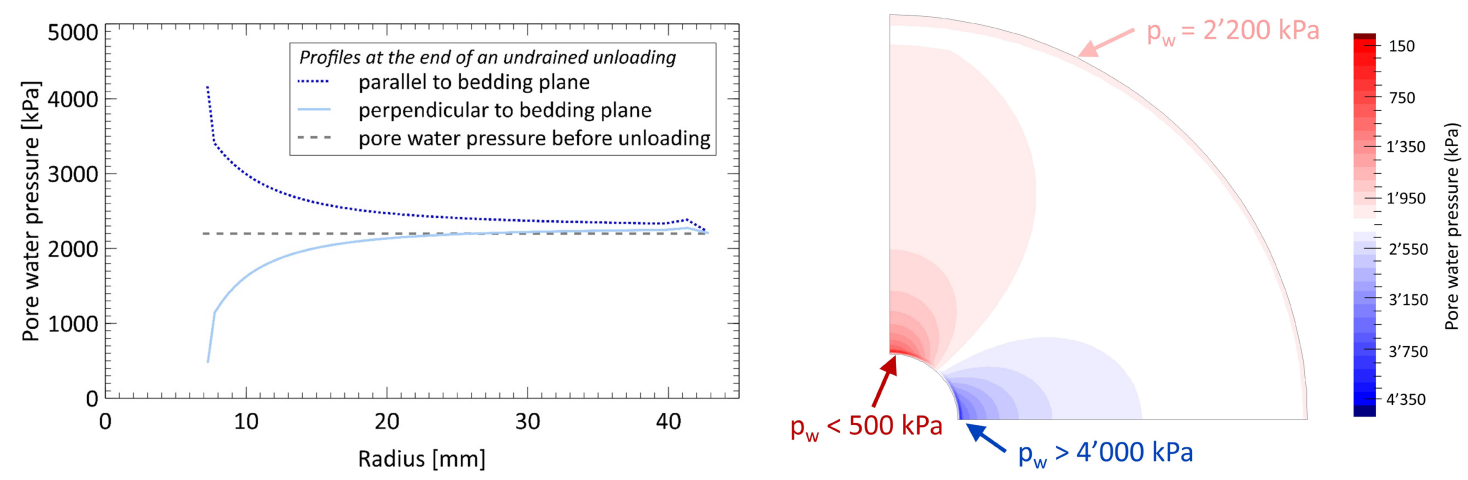

Figure 16. Pore water pressure profiles (left) and spatial distribution (right) at the end of an undrained unloading - stiffness anisotropic model.

Unfortunately, this stiffness anisotropic constitutive model does not consider plasticity. Constitutive models considering an anisotropy of stiffness in the matrix as well as strength and hydraulic anisotropies along bedding planes have been recently developed (Souley and al. 2017, Ismael and Konietzky 2019). Further computations will be performed with this kind of model, e.g. the one developed to model the Callovo-Oxfordian Clay response during the excavation of galleries at Meuse/Haute-Marne URL, France (Souley and al. 2017).

\section{Conclusion}

In the context of nuclear waste storage, hollow cylinder tests were carried out on Boom Clay samples to simulate tunnel excavation. This experimental work as well as in-situ observations at Mol URL have underlined a significant influence of the bedding planes on the convergence and the development of the damaged zone. Samples cored perpendicularly to the bedding (mimicking shafts) show an isotropic behavior, while samples cored along the bedding (that mimic horizontal galleries) exhibit a higher convergence in the direction parallel to the 
bedding with an eye-shape damaged zone.

Numerical simulations were performed to determine whether the strength and/or permeability anisotropies related to the bedding planes could explain this orientationdependent response.

For samples cored perpendicular to the bedding, a conventional isotropic elastoplastic model with Boom Clay usual parameters provides unsurprisingly a relatively good agreement with the experimental measurements. The results highlight the competing impact of the hydro-mechanical coupling occurring during the unloading, on the one hand; and of the drainage towards the central hole, on the other hand. Accordingly, the unloading rate is found to influence the displacement and the plastic zone extent. Due to the volumetric strain change generated during the unloading, a higher unloading rate produces greater displacements and extent of the plastic zone, which is in accordance with recent experimental results.

However, for samples and galleries driven parallel to the bedding planes, numerical simulations considering a strength and/or hydraulic anisotropy show a significant discrepancy with both experimental and in-situ observations. The computed convergence around the central hole as well as the extent of the plastic zone are higher in the direction perpendicular to the bedding, just the opposite to the laboratory observations (i.e. larger in the direction parallel to the bedding). This statement is not software dependent. As stiffness anisotropy may play a major role in the hydromechanical coupling during unloading, it could influence the failure mechanism and should be further investigated. Upcoming work will be carried out with a model including as well stiffness anisotropy.

This work is part of a research project funded by the Belgian National Agency for Radioactive Waste and enriched Fissile Material ONDRAF/NIRAS. The authors are grateful to Shuang You who performed the CT scan analysis that provided the experimental results. 
Bastiaens W, Bernier F, Buyens M, Demarche M, Li X.L, Linotte J.M, Verstricht J. (2003). The connecting gallery-the extension of the HADES underground research facility at Mol, Belgium. EURIDICE report 03-294.

Bastiaens W, Bernier F, Li X.L. (2007). SELFRAC: Experiments and conclusions on fracturing, self-healing and self-sealing processes in clays. Physics and Chemistry of the Earth, 32(8-14), 600-615. https://doi.org/10.1016/j.pce.2006.04.026

Bernier F, Li X.L, Verstricht J, al. (2003). CLIPEX: Clay Instrumentation Programme for the Extension of an Underground Research Laboratory. Luxembourg: European Communities EUR 20619.

Bernier F, Li X.L, Bastiaens W. (2007). 25 years' geotechnical observation and testing in the Tertiary Boom Clay formation. Géotechnique, 57(2), 229-237.

Blümling P, Bernier F, Lebon P, Martin D.C. (2007). The excavation damaged zone in clay formations time-dependent behaviour and influence on performance assessment. Physics and Chemistry of the Earth, 32(8-14), 588-599.

Chen G, Sillen X, Verstricht J, \& Li X. (2011). ATLAS III in situ heating test in boom clay: Field data, observation and interpretation. Computers and Geotechnics, 38(5), 683696. https://doi.org/10.1016/j.compgeo.2011.04.001

Coll C. (2005). Endommagement des roches argileuses et perméabilité induite au voisinage d'ouvrages souterrains. Grenoble: Université Joseph Fourier - Laboratoire Sols, Solides, Structures.

Dao L Q. (2015). Etude du comportement anisotrope de l'argile de Boom. Université Paris Est.

François B, Labiouse V, Dizier A, Marinelli F, Charlier R, Collin F. (2014). Hollow cylinder tests on boom clay: Modelling of strain localization in the anisotropic excavation damaged zone. Rock Mechanics and Rock Engineering, 47(1), 71-86. https://doi.org/10.1007/s00603-012-0348-5

Giraud A, Picard J.M, Rousset G. (1993). Time dependent behavior of tunnels excavated in porous mass. International Journal of Rock Mechanics and Mining Sciences \& Geomechanics Abstracts, 30(7), 1453-1459.

Hall S A. (2006). A methodology for 7D warping and deformation monitoring using timelapse seismic data. Geophysics, 71(4), 021-031.

Hall S A, Lenoir N, Viggiani G, Desrues J, Bésuelle P. (2009). Strain localisation in sand under triaxial loading: Characterisation by x-ray micro tomography and 3D Digital 
Image Correlation. Proceedings of the 1st International Symposium on Computational Geomechanics (ComGeo I). Juan-les-Pins, Cote d'Azur, France. 239-247.

Horseman S.T, Winter M.G, Enwistle D.C. (1987). Geotechnical characterization of boom clay in relation to the disposal of radioactive waste. Luxembourg: Office for Official Publications of the European Communities, EUR 10987 EN.

Ismael M, Konietzky H. (2019). Constitutive model for inherent anisotropic rocks : Ubiquitous joint model based on the Hoek-Brown failure criterion. Computers and Geotechnics 105, 99-109. https://doi.org/10.1016/j.compgeo.2018.09.016

Jaeger J.C. (1960). Shear failure of anisotropic rocks. Geological Magazine, 97(1), 65-72. Kivell S. (2015). Numerical Modelling of Excavation Galleries in Anisotropic Clay Formations. Master Thesis. Lausanne, EPFL.

Labiouse V, Sauthier C, You S. (2014). Hollow cylinder simulation experiments of galleries in boom clay formation. Rock Mechanics and Rock Engineering, 47(1), 43-55. https://doi.org/10.1007/s00603-012-0332-0

Labiouse V, Vietor T. (2014). Laboratory and in situ simulation tests of the excavation damaged zone around galleries in opalinus clay. Rock Mechanics and Rock Engineering, 47(1), 57-70. https://doi.org/10.1007/s00603-013-0389-4

Li X.L. (2013). TIMODAZ: A successful international cooperation project to investigate the thermal impact on the EDZ around a radioactive waste disposal in clay host rocks. Journal of Rock Mechanics and Geotechnical Engineering, 5(3), 231-242. https://doi.org/10.1016/j.jrmge.2013.05.003

Oka F, Kimoto S, Kobayashi H, Adachi T. (2002). Anisotropic behavior of soft sedimentary rock and a constitutive model. Soils and Foundations, 42(5), 59-70.

Peguiron F, Labiouse V. (2020). Analytical solution for the undrained unloading of hollow cylinders in porous elastoplastic media (manuscript in preparation for the International Journal for Numerical and Analytical Methods in Geomechanics)

Peguiron F, Labiouse V. (2021). In situ tomography of thick-walled hollow cylinder tests on Boom Clay samples cored parallel and perpendicular to the bedding (future publication)

Sainsbury B.L., Sainsbury D.P. (2017). Practical Use of the Ubiquitous-Joint Constitutive Model for the Simulation of Anisotropic Rock Masses. Rock Mechanics and Rock Engineering, 50, 1507-1528. https://doi.org/10.1007/s00603-017-1177-3Souley M, Seyedi D, Vu M N, Kazmierczak J-B, Armand G. (2017). Anisotropic 
hydromechanical modelling of a deep drift at the Meuse/Haute-Marne URL. In Clay Conference. Davos.

Truty A, Zimmermann Th, Podlés K, Obrzud R. (2018). ZSOIL 2018 Manual - Theory. Elmepress International. Lausanne, Zace Services Ltd, Software engineering. You S, Ji H, Labiouse V, Hall S, Viggiani G. (2015). Quantitative analysis of deformation in hollow cylinder tests on anisotropic clay formations. International Journal of Mining Science and Technology, 25(2), 299-303. https://doi.org/10.1016/j.ijmst.2015.02.020 